RU Лингвистические средства создания образа В. В. Путина в английском языке (на материале твиттер-аккаунта Д. Д. Трампа)

Кочерган А. М., Родина Е. И.

\begin{abstract}
Аннотация. Цель исследования состоит в раскрытии образа В. В. Путина на международной арене с помощью комплексного лингвистического анализа, проводимого на разных уровнях английского языка. Научная новизна заключается в том, что впервые были проанализированы лингвистические средства графического, морфологического, лексического, стилистического, синтаксического и семантического уровней, взятые из твиттер-аккаунта Д. Трампа, которые раскрывают образ В. В. Путина. Полученные результаты показали, что образ действующего президента Российской Федерации демонстрируется и с отрицательной, и с положительной стороны, а доминирующими уровнями являются лексико-стилистический и собственно лексический соответственно.
\end{abstract}

\title{
Linguistic Means for Creating V. V. Putin's Image in English (by the Material of D. J. Trump's Twitter Account)
}

\author{
Kochergan A. M., Rodina E. I.
}

\begin{abstract}
The purpose of the study is to shed light on Vladimir Putin's image on the international scene with the help of a comprehensive linguistic analysis conducted at different levels of the English language. The study is novel in that it is the first to analyse the linguistic means of graphic, morphological, lexical, stylistic, syntactic and semantic levels taken from D. Trump's Twitter account, which help to construct V. V. Putin's image. The attained results have shown that the image of the current president of the Russian Federation is shown from both negative and positive sides and the prevalent levels are lexico-stylistic and lexical as such, respectively.
\end{abstract}

\section{Введение}

Политическая коммуникация все более привлекает внимание исследователей самых разных областей научного знания, поскольку в современном мире средства массовой информации и социальные сети оказывают мощнейшее влияние на общественное сознание, «что в свою очередь играет одну из определяющих ролей в формировании общественного мнения и формулировании общественных интересов граждан» [2, с. 991].

Связь между языком и политикой очевидна: «...ни один политический режим не может существовать без коммуникации» [8, с. 17]. Более того, можно утверждать, что «специфика политики, в отличие от ряда других сфер человеческой деятельности, заключается в её преимущественно дискурсивном характере: многие политические действия по своей природе являются речевыми действиями» [Там же].

Актуальность темы определяется поворотом современного языкознания в сторону междисциплинарности, когда интерес к политическому дискурсу достаточно высок в силу непростой ситуации на международной арене, в которой оказалась Россия после присоединения Республики Крым и введения санкций против нашей страны в 2014 году. Данная тематика была освящена в официальных зарубежных и отечественных документах с разных, иногда полностью противоположных, точек зрения и до сих пор не потеряла своей актуальности. Президент Российской Федерации играет первостепенную роль в создании образа нашей страны на мировом уровне, и изучение высказываний, относящихся к В. В. Путину, позволяет пролить свет на отношение мирового сообщества к России в целом. Лингвистическая составляющая работы вносит вклад в анализ языковых средств, специфичных для Д. Трампа как политического деятеля, которые являются частью исследования, посвященного политическому дискурсу в целом.

Задачи настоящего исследования: проанализировать лингвистические средства создания отрицательного образа В. В. Путина; проанализировать лингвистические средства создания положительного образа В. В. Путина; 
обобщить полученные результаты и представить образ президента России, основанный на анализе твиттераккаунта Д. Трампа на материале английского языка.

Использованные методы исследования включают метод сплошной выборки, а также методы стилистического и лексико-семантического анализа.

Теоретической базой исследования послужили работы А. Н. Баранова [1], Е. И. Шейгал [8], В. И. Карасика [3] и П. Серио [7], посвященные изучению политического дискурса как речевой деятельности, рассматриваемой с разных точек зрения. Для А. Н. Баранова и Е. И. Шейгал политический язык - это особая знаковая система, «совокупность знаков, образующих семиотическое пространство политического дискурса» [8, с. 22], В. И. Карасик представляет язык политики в качестве разновидности статусно-ориентированного общения [3]. П. Серио описывает политический дискурс как сферу преимущественного употребления некоторых языковых форм и речевых приемов [7]. Кроме того, учитывались работы П. Б. Паршина, который подвергает сомнению существование политического языка как феномена [6]. Важным аспектом исследования явилась методика комплексного анализа, примененная для изучения рекламного дискурса в работах Л. А. Кочетовой [5] и А. М. Кочерган [4].

Практическая значимость работы: материалы исследования могут быть использованы в вузах гуманитарного направления при изучении спецкурсов и спецсеминаров по стилистике английского языка, теоретическому и практическому анализу текста и дискурс-анализу. Полученные данные могут найти применение в процессе учебно-методической деятельности при создании учебников и учебных пособий по общей теории дискурса, политическому дискурсу, дискурсивному анализу и анализу текста.

\section{Лингвистические средства создания отрицательного образа В. В. Путина}

Наше исследование посвящено лингвистическим средствам создания образа действующего президента Российской Федерации на международной арене на основе высказываний Д. Д. Трампа, опубликованных в его твиттер-аккаунте в 2014-2017 гг. Так, в течение нескольких лет Дональд Трамп ведёт твиттер-дипломатию, за счет которой смог набрать аудиторию в 42,5 миллиона читателей. В среднем он каждый день выкладывает по 5-6 твитов, где демонстрирует своё отношение к основным событиям, происходящим в мире, включая Россию и ее президента. Высказывания Д. Д. Трампа вносят существенный вклад в создание определенного имиджа России за счет образа В. В. Путина как основного представителя страны на международной арене.

В начале своей политической карьеры Д. Д. Трамп был категорично настроен против В. В. Путина. Так, в марте 2014, в своём твиттер-аккаунте он написал обращение к правившему в тот момент президенту США, Бараку Обаме, следующие строки: President Obama, be cool, be smart, be sharp and you can beat Putin at his own game. IT CAN BE DONE [10]! / Президент Обама, будь хладнокровным, будь умным, будь резким, и ты сможешь победить В. В. Путина в его игре. ЭТО ВОЗМОЖНО! Императивная конструкция, основанная на синтаксическом параллелизме (be cool, be smart, be sharp) направлена на усиление экспрессивности речи и подчеркивает эмоциональное состояние говорящего. Метафора beat Putin at his own game, посредством которой Д. Д. Трамп сравнивает политику В. В. Путина с игрой, создает образ хитрого и коварного политика, играющего в политические игры для достижения своих целей. Глагол beat раскрывает отношение говорящего к предмету высказывания за счет внутренней семантики лексической единицы. Капитализация в завершающей фразе IT CAN BE DONE воздействует на читателя как повышение голоса при звучащей речи, привлекая внимание читателя к основной идее высказывания. Целесообразно предположить, что основной интенцией употребления разноуровневых лингвистических средств является усиление экспрессивности речи с целью призвать Барака Обаму к активным действиям, направленным на борьбу с Россией в лице ее президента.

В разговоре с Д. Д. Трампом американский журналист и политический обозреватель Билл О’Райли применяет простую метафору, называя В. В. Путина убийцей (killer), показывая негативное отношение к лидеру нашей страны. Д. Д. Трамп в ответ на высказывание корреспондента сравнивает политику России и США, говоря: «Убийц много. Вы думаете, что наша страна такая невиновная?» Таким образом, Д. Д. Трамп делает отсылку на политику президента Обамы: In an interview with Bill O’Reilly, when his interviewer says Putin is "a killer", Trump responds: “There are a lot of killers. You think our country's so innocent?” [9]. Антонимические лексические единицы killer - innocent подчеркивают напряженные отношения между вышеупомянутыми странами. Эпитет innocent призван оправдать В. В. Путина в глазах зрителей. Следует отметить, что в данном вопросе Д. Д. Трамп употребляет непрямой порядок слов, опуская вспомогательный глагол do, что придает речи неформальный характер.

15 августа 2017 года Д. Д. Трамп публикует твит, в котором образ России персонифицируется - to anger Russia, таким образом, происходит отсылка на В. В. Путина, которого можно легко разозлить: According to report just out, President Obama knew about Russian interference 3 years ago but he didn't want to anger Russia! [Ibidem]. / Согласно только что опубликованному отчету, президент Обама знал о вмешательстве России 3 года назад, но не хотел рассердить Россию!

Говоря об отношениях Барака Обамы и В. В. Путина, Д. Д. Трамп отмечает конфронтацию между ними. Так, он использует метонимию zero chemistry, что в переводе на русский означает отсутствие химии, мы же понимаем это как невосприятие друг друга. Does the Fake News Media remember when Crooked Hillary Clinton, as Secretary of State, was begging Russia to be our friend? Obama tried also, but he had zero chemistry with Putin [Ibidem]. / Помнят ли фальшивые СМИ, когда Лживая Хиллари Клинтон, будучи госсекретарем, умоляла Россию быть нашим другом? Барак Обама тоже пытался, но у него не сложились отношения с В. В. Путиным. 
В одном из своих твитов Д. Д. Трамп отмечает, что В. В. Путин давно ведёт кампанию, направленную на подрыв политического строя страны. Так, он употребляет эпитет anti-US (антиамериканский): Russia started their anti-US campaign in 2014, long before I announced that I would run for President [Ibidem]. / Россия начала свою антиамериканскую кампанию в 2014 году, задолго до того, как я объявил, что буду баллотироваться в президен$m b$. В данном высказывании негативная коннотация создается на морфологическом уровне с помощью префикса с отрицательной коннотацией anti.

Таким образом, отрицательный образ В. В. Путина создается на различных уровнях языка: лексическом, стилистическом, синтаксическом и семантическом. Доминирующим языковым уровнем является лексикостилистический, где мы видим использование иронических метафор, например, beat Putin at his own game и zero chemistry, и лексических единиц с отрицательной коннотацией и семантикой борьбы, например anger и killer.

\section{Лингвистические средства создания положительного образа В. В. Путина}

Несмотря на то, что в начале своей карьеры Д. Д. Трамп был настроен против В. В. Путина, мы видим, как меняется его отношение, когда Д. Д. Трамп называет В. В. Путина героем России в связи с присоединением Крыма к Российской Федерации, что было большим достижением для России и, в частности, для В. В. Путина. Д. Д. Трамп же, обнаружив слабость Америки, обвинил во всем Барака Обаму, которого ранее поддерживал и в которого, казалось, верил: Putin has become a big hero in Russia with an all-time high popularity. Obama, on the other hand, has fallen to his lowest ever numbers. SAD [Ibidem]. / В. В. Путин стал в России большим героем, пользующимся небывало высокой популярностью. Барак Обама, с другой стороны, достиг самого низкого уровня за всю историю. ПЕЧАЛЬНО. Помимо метафоры big hero, направленной на восхваление В. В. Путина, Д. Д. Трамп использовал гиперболу all-time high popularity с семантикой наибольшей меры чего-либо, состоящую из существительного с элементом all и прилагательного high. Противопоставление, основанное на сравнении двух лидеров, реализуется с помощью контрастивного словосочетания on the other hand и контекстуальных антонимических фраз has become a big hero и has fallen to his lowest ever numbers. Превосходная степень прилагательного low указывает на низкую популярность Барака Обамы, а в сочетании с наречием ever и существительным пuтbers служит для создания литоты, что работает на усиление контраста двух лидеров. Капитализация $S A D$ подчеркивает негативное отношение Д. Д. Трампа к сложившейся ситуации. Таким образом, мы можем сделать вывод о том, что Дональд Трамп признал величие В. В. Путина на мировой арене в отдельно взятый период времени.

В последующих твитах мы видим, что Д. Д. Трамп, признав мощь и силу В. В. Путина, способного захватывать огромные территории, использует метонимию, говоря о том, что Россия представляет собой огромную проблему для Америки. Он начинает опасаться В. В. Путина и, вполне вероятно, осознает необходимость считаться с президентом Российской Федерации: March 24, 2014: Trump states on “Fox \& Friends” that “Russia's our biggest problem, and Russia is, you know, really something” [Ibidem]. / 24 марта 2014 года: Д. Д. Трамп заявляет в "Fox \& Friends", что «Россия - наша самая большая проблема, а с Россией надо считаться». В данном случае прилагательное big, употребленное в превосходной степени, которое относится к существительному problem, демонстрирует, насколько сильно Д. Д. Трамп обеспокоен мощью России. Лексический повтор названия страны Russia служит этой же цели. Неопределенное местоимение something, усиленное наречием really, подчеркивает волнение будущего американского президента по поводу возрастающей мощи России. Прямое обращение уоu know делает данное высказывание живым и естественным, связывает говорящего с потенциальной аудиторией. Таким образом, данное высказывание Д. Д. Трампа о России косвенно подразумевает его отношение к В. В. Путину и характеризует президента России как фигуру значительного масштаба на международной арене, которая может вызвать беспокойство у других стран.

В 2015 году мы видим, как налаживаются отношения между В. В. Путиным и Д. Д. Трампом. December 17, 2015: After Putin describes Trump as a "talented person" and "the absolute leader" in the presidential race, Trump responds: "It is always a great honor to be so nicely complimented by a man so highly respected within his own country and beyond” [Ibidem]. / 17 декабря 2015 г. После того, как В. В. Путин описывает Д. Д. Трампа как «талантливого человека» и «абсолютного лидера» в президентской гонке, Дональд Трамп отвечает: «Всегда большая честь получить такой приятный комплимент от человека, столь уважаемого в своей собственной стране и за ее пределами». В ответ на положительное отношение В. В. Путина, Д. Д. Трамп называет его глубокоуважаемым человеком, применяя эпитет highly respected, чтобы подчеркнуть степень уважения, проявленную к Путину. При этом он уточняет, что президент РФ пользуется уважением не только в своей стране, но и за рубежом (within his own country and beyond), что значительно «добавляет баллы» В. В. Путину как лидеру одной из мировых держав. Также в данном предложении Д. Д. Трамп использует выражение высокого стиля great honor, посредством которого выражает свою признательность по отношению к В. В. Путину. Наречие nicely служит этой же цели, подчёркивая положительный настрой в отношении В. В. Путина.

В 2016 году Д. Д. Трамп не только одобряет В. В. Путина, но и возвышает его, сравнивая с действующим президентом США - Бараком Обамой. September 7, 2016: At NBC's commander-in-chief forum, Trump states that "Putin has been a leader far more than our president has been a leader" [Ibidem]. / 7 сентября 2016 г.: на форуме главнокомандующих NBC Д. Д. Трамп заявляет, что «В. В. Путин был лидером в гораздо большей степени, чем наш президент был лидером». Таким образом, Д. Д. Трамп сравнивает двух лидеров посредством наречия far в сочетании со сравнительной формой прилагательного тоге и сравнительным союзом than в пользу В. В. Путина. Следует отметить, что он намеренно использовал лексический повтор в словах has been a leader, для того чтобы подчеркнуть лидерские качества В. В. Путина. 
Став президентом США, Д. Д. Трамп не отказался от своих намерений продолжать налаживание отношений с Россией в лице В. В. Путина. Так, он говорит о возможности отмены санкций к России. Таким образом, мы можем отнести эпитет great к В. В. Путину: Trump tells the Wall Street Journal he may lift sanctions on Russia: "If you get along and if Russia is really helping us, why would anybody have sanctions if somebody's doing some really great things?” [Ibidem]. / Д. Д. Трамn сообщает Wall Street Journal, что может отменить санкции в отношении России: «Если можно найти общий язык, и если Россия действительно нам помогает, зачем кому-то нужны санкции, если дела идут на самом деле хорошо?». В данном случае Д. Д. Трамп использует фразовый глагол get along, чтобы отметить вероятность дружеских отношений с Россией в лице В. В. Путина, который стремится помочь США, что на лексическом уровне выражено глаголом help. Использование времени Present Continuous подчеркивает, что то, о чем говорит американский президент, актуально в данный момент времени. Повтор наречия really, относящегося к глаголу help и к фразе great things, усиливает значения данных лексических единиц. «Сильное прилагательное» (англ. strong или non-gradable adjective) great в сочетании с существительным с размытой семантикой thin акцентирует важность того, что делает В. В. Путин.

14 ноября 2017 года Д. Д. Трамп в очередной раз показывает свой положительный настрой в отношении В. В. Путина. Во время своей поездки в Азию он говорит о В. В. Путине следующее: We seem to have a very good feeling for each other, a good relationship considering we don't know each other well. I think it's a very good relationship [Ibidem]. / Кажется, мы очень хорошо друг к другу относимся, у нас хорошие отношения, несмотря на то, что мы плохо друг друга знаем. Я думаю, что это очень хорошие отношения. Лексический повтор good relationship коррелирует с фразой a good feeling с интенсификатором very, что подчеркивает положительное отношение Д. Д. Трампа к российскому президенту. Реципрок each other имплицирует надежду на взаимное расположение друг к другу американского и российского лидеров.

Таким образом, основным средством создания положительного образа В. В. Путина является лексический уровень, в котором используются лексические единицы возвышенного стиля или похвала, а также прилагательные превосходной степени и слова с положительной семантикой. Языковые единицы данного уровня дополнены средствами стилистического, синтаксического и семантического уровней.

\section{Заключение}

Проанализировав сложившийся образ В. В. Путина на основе твиттер-аккаунта Д. Д. Трампа, мы можем сделать следующие выводы, что президент России воспринимается неоднозначно как самим Д. Д. Трампом, так и американскими журналистами, которые интервьюировали американского президента.

Исходя из проанализированного материала, можно заключить, что в начале своей карьеры Д. Д. Трамп был настроен крайне негативно по отношению к В. В. Путину, что отражено в его ранних твитах. И даже несмотря на изменения его отношения в сторону доброжелательного, время от времени Д. Д. Трамп проявляет агрессию к политическим действиям В. В. Путина, что находит отражение на морфемном уровне с помощью использования префикса anti; лексическом, представленном языковыми единицами с отрицательной коннотацией; стилистическом уровне, где используются тропы, преимущественно метафоры с ироническим подтекстом; синтаксическом, например, эллиптические предложения; графическом, представленном капитализацией; а также семантическом.

Однако, в целом, Д. Д. Трамп настроен на улучшение отношений с Россией, что подчеркивается преимущественным большинством его твитов, в которых он восхваляет и восхищается президентом России и сравнивает его с американским президентом в пользу первого. На лингвистическом уровне данная семантика выражена на всех уровнях языка, начиная от морфемного до семантического. Однако доминирующим уровнем является лексический за счет употребления большого количества лексических единиц с положительной семантикой, включая превосходную степень прилагательных, слова высокого стиля и т.д. Таким образом, в Америке за счет влияния Д. Д. Трампа образ В. В. Путина транслируется как образ возможного друга, сильного лидера, высокоинтеллектуального человека, героя и высокоуважаемого человека.

Мы видим перспективы дальнейшего исследования в раскрытии образа В. В. Путина на основе зарубежных СМИ, как американских, так и СМИ других стран и сопоставлении различных интерпретаций образа российского президента с помощью комплексного лингвистического анализа.

\section{Источники | References}

1. Баранов А. Н. Политический дискурс: прощание с ритуалом // Человек. 1997. № 6. С. 108-117.

2. Гуржий Д. А. Влияние СМИ на формирование общественного мнения // Молодой ученый. 2015 . № 12 (92). С. 991-993.

3. Карасик В. И. Языковой круг: личность, концепты, дискурс. Волгоград: Перемена, 2002. 477 с.

4. Кочерган А. М. Тактико-стратегическая реализация интенции предложения в англоязычной журнальной рекламе (на материале рекламы товаров, относящихся к предметным областям «красота» и «здоровье»): дисс. .... к. филол. н. Самара, 2018. 190 с.

5. Кочетова Л. А. Английский рекламный дискурс в динамическом аспекте: дисс. ... д. филол. н. Волгоград, 2013. 438 c. 
6. Паршин П. Б. Исследовательские практики, предмет и методы политической лингвистики // Scripta Linguisticae Applicatae. Проблемы прикладной лингвистики / отв. ред. А. И. Новиков. М.: Азбуковник, 2001. C. 181-208.

7. Серио П. О языке власти: критический анализ // Философия языка: в границах и вне границ: в 4-х т. / отв. ред. Ю. С. Степанов. Х.: Око, 1993. Т. 1. С. 83-100.

8. Шейгал Е. И. Семиотика политического дискурса: монография. Волгоград: Перемена, 2000. 367 с.

9. Donald Trump's Statements on Putin/Russia/Fake News Media [Электронный ресурс] // Lawfare. 2021. April 11. URL: https://www.lawfareblog.com/donald-trumps-statements-putinrussiafake-news-media (дата обращения: 20.03.2021).

10. Strong D. [Электронный ресурс] // Twitter. 2020. 26 July. URL: https://twitter.com/Dianastrong2011/status/ 1287380339615305729 (дата обращения: 20.03.2021).

\section{Информация об авторах | Author information}

RU Кочерган Александра Михайловна ${ }^{1}$, к. филол. н.

Родина Екатерина Игоревна ${ }^{2}$

1,2 Санкт-Петербургский гуманитарный университет профсоюзов

EN Kochergan Alexandra Mikhailovna ${ }^{1}, \mathrm{PhD}$

Rodina Ekaterina Igorevna ${ }^{2}$

${ }^{1,2}$ St. Petersburg University of the Humanities and Social Sciences

${ }^{1}$ sasha-kochergan@inbox.ru, ${ }^{2}$ kathrine.rodina@mail.ru

\section{Информация о статье | About this article}

Дата поступления рукописи (received): 25.03.2021; опубликовано (published): 31.05.2021.

Ключевые слова (keywords): политический дискурс; лингвистический анализ; интенция высказывания; изобразительно-выразительные средства; твиттер-аккаунт Д. Трампа; political discourse; linguistic analysis; intention of utterance; figurative-expressive means; D. Trump's Twitter account. 